\title{
Identification and reciprocal introgression of a QTL affecting body mass in mice
}

\author{
Julian K. Christians ${ }^{\mathrm{a} *}$, Kellie A. Rance ${ }^{\mathrm{a}, \mathrm{b}}$, Sara A. KnotT ${ }^{\mathrm{a}}$, \\ Pat M. Pignatelli ${ }^{\mathrm{a}, \mathrm{c}}$, Fiona Oliver ${ }^{\mathrm{a}}$, Lutz BüNGER ${ }^{\mathrm{a}, \mathrm{d}}$ \\ ${ }^{a}$ Institute of Cell, Animal and Population Biology, University of Edinburgh, \\ Ashworth Laboratories, King's Buildings, West Mains Road, Edinburgh, EH9 3JT, UK
}

(Received 12 January 2004; accepted 27 April 2004)

\begin{abstract}
The aim of this study was to examine the effects of a QTL in different genetic backgrounds. A QTL affecting body mass on chromosome 6 was identified in an $F_{2}$ cross between two lines of mice that have been divergently selected for this trait. The effect of the QTL on mass increased between 6 and 10 weeks of age and was not sex-specific. Body composition analysis showed effects on fat-free dry body mass and fat mass. To examine the effect of this QTL in different genetic backgrounds, the high body mass sixth chromosome was introgressed into the low body mass genetic background and vice versa by repeated marker-assisted backcrossing. After three generations of backcrossing, new $\mathrm{F}_{2}$ populations were established within each of the introgression lines by crossing individuals that were heterozygous across the sixth chromosome. The estimated additive effect of the QTL on 10-week body mass was similar in both genetic backgrounds and in the original $\mathrm{F}_{2}$ population (i.e., $\sim 0.4$ phenotypic standard deviations); no evidence of epistatic interaction with the genetic background was found. The $95 \%$ confidence interval for the location of the QTL was refined to a region of approximately $7 \mathrm{cM}$ between D6Mit268 and D6Mit123.
\end{abstract}

quantitative trait loci / introgression / epistasis / body mass

\section{INTRODUCTION}

Many traits of medical, agricultural or evolutionary importance vary continuously rather than discreetly and numerous studies have identified

\footnotetext{
*Corresponding author: julian.christians@ed.ac.uk Present addresses:

${ }^{\mathrm{b}}$ Aberdeen Centre for Energy Regulation and Obesity (ACERO), Energy Balance and Obesity Division, Rowett Research Institute, Greenburn Road, Bucksburn, Aberdeen, AB21 9SB, UK

${ }^{\mathrm{c}}$ Liverpool School of Tropical Medicine, Pembroke Place, Liverpool L3 5QA, UK

d Animal Breeding \& Genetics Dept., Animal Biology Division, Scottish Agricultural College, Bush Estate, Penicuik, EH26 0PH, UK
} 
chromosomal regions that influence variation in a wide range of such traits (i.e., quantitative trait loci, or QTL) [20]. The vast majority of such studies have examined QTL within a single genetic background, generally an $\mathrm{F}_{2}$ or backcross population between two lines or populations. However, it would be expected that the effects of QTL would depend on the genetic background, given that the expressivity, penetrance and dominance of Mendelian mutations are frequently found to be affected by modifier genes [22]. Although a number of studies have found evidence of epistasis between QTL or marker loci (e.g., $[1,5,17,24,30])$, the statistical power to detect epistasis is generally very low [20] making it difficult to study specific interactions [24,30]. An alternative to examining pair-wise interactions between loci in a mapping population is to focus on a single QTL and to introgress the QTL alleles into different genetic backgrounds. This approach is of greater relevance to marker-assisted introgression of beneficial alleles in agricultural species $[12,14,31]$ and to the use of transgenic techniques to identify genes underlying QTL [10].

In the present study we have used the introgression approach to test for epistasis. We have identified a QTL affecting body mass on chromosome 6 in an $\mathrm{F}_{2}$ cross between two lines that have been divergently selected for body weight. Many studies have performed genome-wide scans for body mass QTL [7] and yet relatively few have gone on to replicate findings or to examine the effects of QTL in different genetic backgrounds. We therefore introgressed the sixth chromosome from each of the parental lines into the genetic background of the other parental line, i.e., the 'high' QTL allele into the 'low' background and vice versa. We tested the QTL in each of the parental lines because we hypothesised that these might harbour modifier loci of the QTL. For example, selection for high body mass would not only select for 'high' alleles at the QTL, but would also select for modifier alleles at other loci that either enhanced the effect of the QTL's 'high' allele, or reduced the effect of the 'low' allele.

\section{MATERIALS AND METHODS}

\subsection{Animal maintenance}

Mice were fed a standard breeding diet (Rat and Mouse \#3, Special Diet Services, UK) ad libitum. Further details regarding animal maintenance are described in [16]. The original $F_{2}$ population (described below) was raised in an older facility whereas in 1994 and 1995 all lines were transferred by embryotransfer to a newly-built facility with a high health standard which resulted 
in lower intergenerational variation in body mass [3]. The introgression lines, the new $\mathrm{F}_{2}$ populations, and contemporaneous high and low lines (described below) were all raised in this new unit.

\subsection{Original $F_{2}$ population}

The two parental lines consist of a high (PH) and a low body mass line (PL) derived from the same base population (an F1 derived from two inbred lines, JU and CBA, crossed to an outbred line, CFLP) followed by divergent longterm ( $>50$ generations) selection on protein mass and later on body weight at 70 days [3,27]. An $F_{2}$ population was derived from the inbred low line (generation 7 post-inbreeding) and the outbred high line (generation 52 of selection; attempts to produce an inbred high line had been unsuccessful) [23]. Body mass was recorded at 3, 6 and 10 weeks of age in $334 \mathrm{~F}_{2}$ individuals from first, second and third parity litters of 18 families. To estimate fat content and fat-free dry body mass, animals were starved overnight and killed at 10 weeks of age and then freeze-dried. Carcass fat percentage was calculated using the following formula from [15] (see also [2,4]):

Fat percentage $=$

[(freeze-dried weight $\times 1.13) /$ starved weight $)-0.302] \times 100$.

\subsection{Coarse genome-wide scan}

Eighteen autosomal microsatellite markers (on chromosomes 3, 5, 6, 7, 9, $10,12,13,14,15$, and 19) that were polymorphic between the high and low lines were identified and genotyped within the original $F_{2}$ population. Markers on other chromosomes were tested for polymorphism but the low frequency of polymorphism precluded a genome-wide scan.

The association between genotype and body mass at 10 weeks of age was examined using single marker analyses. Of the eighteen autosomal markers, the strongest linkage was with markers on chromosome 6 (data not shown), and therefore investigation of this chromosome was intensified and further polymorphic markers were found (see below) to enable interval mapping. More detailed examination of the X-chromosome is described elsewhere [19,23].

\subsection{Reciprocal introgression and new $F_{2}$ populations}

To confirm the existence of the chromosome 6 QTL and to investigate its effect in different genetic backgrounds, the QTL alleles from the high and low 
Table I. Genotyped microsatellite markers on Chromosome 6. Linkage map positions were calculated from the original and new $\mathrm{F}_{2}$ populations using CRIMAP [13] whereas physical map positions were obtained from the Ensembl Mouse Genome Server Database [8].

\begin{tabular}{lcccc}
\hline Marker name & \multicolumn{2}{c}{ Genotyped in } & Linkage map & Physical map \\
& Original $\mathrm{F}_{2}$ & $\mathrm{New} \mathrm{F}_{2}$ & position $(\mathrm{cM})$ & position (MB) \\
\hline D6Mit204 & $\mathrm{Y}$ & $\mathrm{Y}$ & 0.0 & 23.1 \\
D6Mit159 & $\mathrm{Y}$ & $\mathrm{Y}$ & 2.1 & 29.8 \\
D6Mit268 & & $\mathrm{Y}$ & 3.7 & 34.9 \\
D6Mit123 & $\mathrm{Y}$ & $\mathrm{Y}$ & 16.2 & 57.3 \\
D6Mit17 & $\mathrm{Y}$ & & 19.1 & 72.0 \\
D6Mit261 & $\mathrm{Y}$ & $\mathrm{Y}$ & 27.2 & 89.4 \\
D6Mit31 & $\mathrm{Y}$ & & 35.2 & 93.5 \\
D6Mit105 & $\mathrm{Y}$ & & 47.6 & 108.6 \\
D6Mit216 & $\mathrm{Y}$ & $\mathrm{Y}$ & 52.8 & 121.9 \\
D6Mit111 & & $\mathrm{Y}$ & 59.2 & 134.2 \\
D6Mit15 & $\mathrm{Y}$ & $\mathrm{Y}$ & 69.7 & 147.1 \\
\hline
\end{tabular}

lines were introgressed into the opposite background by repeated backcrossing, targeting the entire sixth chromosome. To do so a new $\mathrm{F}_{1}$ population was produced by crossing the contemporaneous inbred low (generation 28 postinbreeding) and high lines (generation 24; an inbred high line was developed subsequent to the original $\mathrm{F}_{2}$ study). Reciprocal backcrosses were performed to each of the parental lines (using both males and females as the recurrent parent) for three further generations, using only individuals that were heterozygous at the following markers: D6Mit204, D6Mit159, D6Mit268, D6Mit123, D6Mit261, D6Mit216, D6Mit111 and D6Mit15. These markers spanned most of chromosome 6 with the largest gap being $25.6 \mathrm{cM}$ between D6Mit261 and D6Mit216 (see Tab. I). To ensure that a double recombination had not occurred within this gap, D6Mit105 was typed in the third backcross generation. In this way, the high allele was introgressed onto the low background to produce a "high in low" (HinL) line and vice versa (LinH line). After three generations of backcrossing (after the $\mathrm{F}_{1}$ ), the random contribution from the introgressed autosomal genome was expected to be about $6.3 \%$ (in addition to the introgressed sixth chromosome).

The third backcross generation was intercrossed (selecting only individuals heterozygous at D6Mit105 and the eight markers described above) to produce $\mathrm{F}_{2}$ populations within each of the lines. In the $\mathrm{LinH}$ line, 10 families yielded 139 individuals from first, second and third litters, whereas in the HinL line the $\mathrm{F}_{2}$ population consisted of 116 individuals from first through fifth litters of 
6 families. Body mass at 10 weeks of age was recorded at each generation and in the new $\mathrm{F}_{2}$ populations.

\subsection{Fixation of QTL allele in the introgressed lines}

Preliminary results from the original and new $\mathrm{F}_{2}$ populations indicated that the QTL was proximal to D6Mit261. Therefore, to fix the QTL allele within each of the introgression lines, individuals that were homozygous for the introgressed allele at D6Mit204, D6Mit159, D6Mit268, D6Mit123 and D6Mit261 were mated with each other. Six and four such matings were set up within the LinH and HinL lines, respectively, and offspring from these matings were weighed at 10 weeks of age.

\subsection{Microsatellite genotyping}

Extraction of genomic DNA from either ear clip or spleen tissue and amplification of microsatellite markers was performed by standard methods. PCR products were separated on $20-\mathrm{cm}$ polyacrylamide gels, stained with ethidium bromide, and photographed under UV light. Photographs of gels were scored twice and ambiguous genotypes were re-amplified.

\subsection{Markers genotyped and linkage map}

The chromosome 6 microsatellite markers genotyped are shown in Table I. There are some differences between the original and new $\mathrm{F}_{2}$ populations because not all of the markers were segregating in the original $F_{2}$ population, and because more even spacing of markers was adopted for the new $\mathrm{F}_{2}$ population. In the original $\mathrm{F}_{2}$ population, only D6Mit204 and D6Mit17 were fixed for different alleles in the two parental lines; as a result, some families are not informative (i.e., not segregating) at the other markers. All of the parents of the new $F_{2}$ populations were heterozygous at all markers and thus all families are informative.

The order of the markers was obtained from the Mouse Genome Database [21] and the Ensembl Mouse Genome Server Database [8]; this order was assumed to be correct since the genetic and physical maps are in agreement. Map positions for these markers were calculated using the software package CRIMAP [13] combining genotypes from the original and new $\mathrm{F}_{2}$ populations (Tab. I). 


\subsection{Interval mapping}

Interval mapping (one- and two-QTL analysis) was performed using the QTL Express package, which is able to accommodate outbred lines (e.g., the high line in the original $\mathrm{F}_{2}$ population) [26]. These analyses fitted additive and dominance effects, as well as the effects of parental pair, sex and a linear covariate for litter size at weaning simultaneously. Significance thresholds for each trait were determined by permuting the marker data [6], using 1000 permutations. Threshold $\mathrm{F}$-values are presented as $\mathrm{F}_{0.05}$ and $\mathrm{F}_{0.01}$ for significance at $\alpha=0.05$ and $\alpha=0.01$, respectively. The two-QTL analysis estimates the effects of two QTL at separate positions simultaneously, examining all possible pairs of locations (on a $1 \mathrm{cM}$ grid), and determines the pair of locations for which the model explains the most variation; this analysis provides F-statistics for the tests of two QTL versus no QTL and of two QTL versus the best oneQTL model. The significance of a second QTL was assessed by comparing the two-QTL versus one-QTL model using the threshold for a single-QTL analysis. Confidence intervals for the location of QTL from interval mapping were calculated from 1000 bootstrapped samples [29].

\subsection{Tests of epistasis}

To test whether the effect of the QTL differed between the two genetic backgrounds (i.e., high or low), a variation of the analysis described in [24] was performed. The additive and dominance coefficients at the position of the QTL (estimated by the combined analysis of the HinL and LinH $\mathrm{F}_{2}$ populations) were exported from QTL Express; the additive coefficient of an individual is the difference between the probabilities of being either homozygote, whereas the dominance coefficient is the probability of being a heterozygote. Tests of epistasis were performed using a general linear model (GLM procedure, [25]) with 10 -week body mass as the dependent variable and the additive and dominance coefficients, line (i.e., LinH or HinL) and the additive by line interaction or the dominance by line interaction as the independent factors. Parental pair (nested within line), sex and litter size at weaning were also included in these analyses.

Scale is a potential problem in this type of analysis [9]. We therefore tested for epistasis using the raw data as well as data standardised to have a mean of 0 and a standard deviation of 1 within each sex and population (see below). 
Table II. Means and standard deviations for body mass and composition at various ages in the original and new $\mathrm{F}_{2}$ populations.

\begin{tabular}{|c|c|c|c|c|c|c|}
\hline & \multicolumn{3}{|c|}{ Females } & \multicolumn{3}{|c|}{ Males } \\
\hline & $N$ & Mean & $\begin{array}{l}\text { Standard } \\
\text { deviation }\end{array}$ & $N$ & Mean & $\begin{array}{l}\text { Standard } \\
\text { deviation }\end{array}$ \\
\hline \multicolumn{7}{|l|}{ Original $F_{2}$ population } \\
\hline 10-week body mass (g) & 156 & 25.9 & 3.8 & 180 & 31.4 & 4.6 \\
\hline 6-week body mass (g) & 156 & 20.9 & 3.1 & 176 & 24.9 & 4.3 \\
\hline 3-week body mass (g) & 153 & 10.0 & 2.1 & 176 & 10.3 & 2.2 \\
\hline Fat-free dry body mass (g) & 148 & 6.6 & 1.0 & 179 & 7.8 & 1.2 \\
\hline Fat content $(\mathrm{g})$ & 148 & 2.1 & 0.8 & 179 & 3.8 & 1.5 \\
\hline \multicolumn{7}{|l|}{$\mathrm{LinH}_{2}$ population } \\
\hline 10-week body mass $(\mathrm{g})$ & 69 & 35.3 & 2.9 & 70 & 43.6 & 4.0 \\
\hline \multicolumn{7}{|l|}{ HinL $F_{2}$ population } \\
\hline 10-week body mass (g) & 39 & 15.5 & 1.5 & 77 & 18.8 & 1.9 \\
\hline
\end{tabular}

\section{RESULTS}

\subsection{Original $F_{2}$ population}

The means and standard deviations for the measured growth traits are shown in Table II. The peak F value (13.6) from the interval mapping analysis of 10 -week body mass exceeded $\mathrm{F}_{0.01}(6.2)$; i.e., there was substantial support for the presence of at least one QTL (Fig. 1A), but the F-value for the addition of a second QTL was not significant $\left(\mathrm{F}=3.4\right.$ vs. $\left.\mathrm{F}_{0.05}=4.6\right)$. As expected, homozygotes for the high-line allele had greater body mass than homozygotes for the low-line allele (Tab. III); the dominance effect was not significantly different from zero (Tab. III). The $95 \%$ confidence interval for the location of the QTL determined by bootstrapping was 1 to $39 \mathrm{cM}$.

When a sex by QTL interaction was included in the model, the estimated additive effects did not differ between the sexes (data not shown). When the sexes were analysed separately, the estimated locations did not differ significantly and fell within the $95 \%$ confidence interval obtained from the combined data (data not shown).

Interval mapping of 6-week body mass yielded similar results to 10-week body mass (Fig. 1A; Tab. III), although the estimated additive effect and statistical support was lower $\left(\mathrm{F}=9.0\right.$ vs. $\left.\mathrm{F}_{0.01}=6.4\right)$. There was no significant linkage with 3 -week mass $\left(F=3.2 v s . F_{0.05}=4.8\right)$. Fat-free dry body mass 


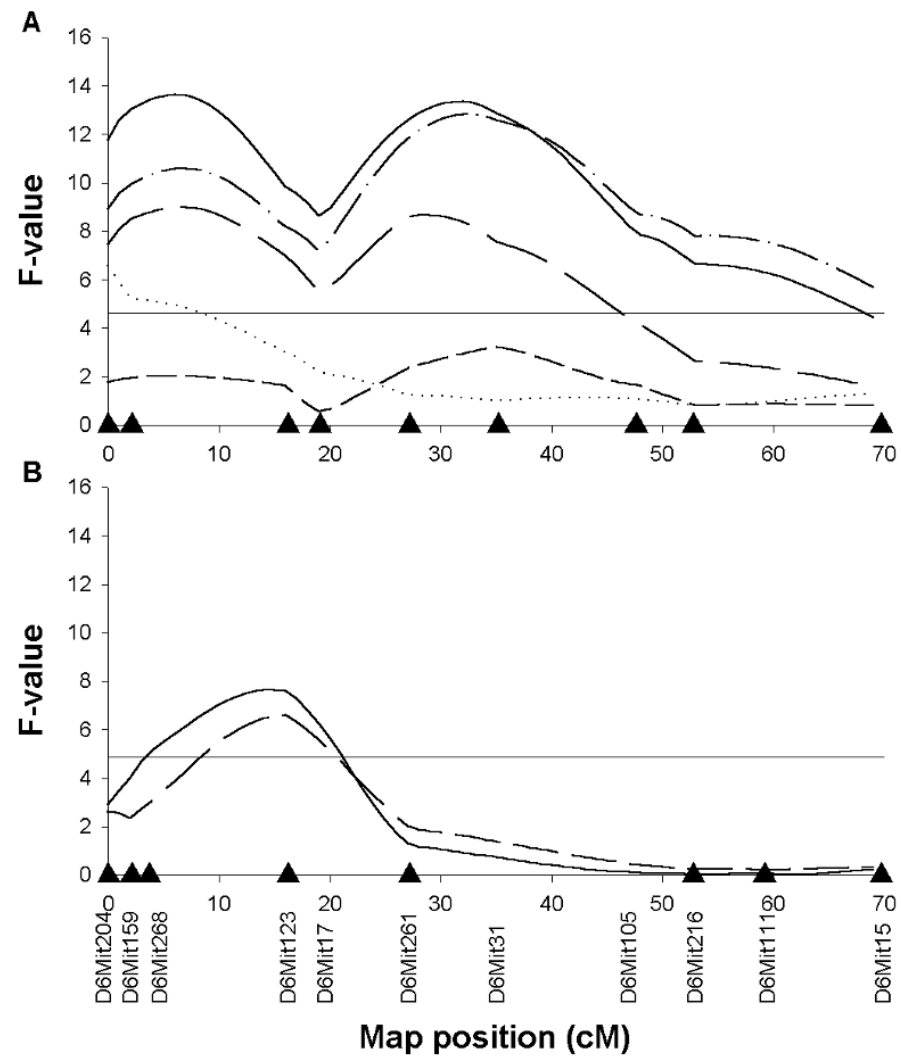

Figure 1. A: F-value plot from interval mapping of 10-week (solid line), 6-week (longdashed line), 3-week (short-dashed line), fat-free dry (dash-dotted line) and fat mass (dotted line) in the original $\mathrm{F}_{2}$ population. B: F-value plot from interval mapping of 10 -week body mass in the LinH (solid line) and HinL (dashed line) $\mathrm{F}_{2}$ populations. Both: Triangles denote the positions of markers typed. The horizontal lines indicate the chromosome-wide 5\% significance level obtained by permutation analysis.

at 10 weeks showed significant linkage $\left(\mathrm{F}=12.8\right.$ vs. $\left.\mathrm{F}_{0.01}=6.1\right)$ and the estimated additive effect (in phenotypic standard deviation units) was similar to that for 10-week body mass (Tab. III). While the estimated location of the QTL for fat-free dry body mass was substantially different than that for 10-week live body mass, the shape of the F-value plot was similar for both traits (Fig. 1A) and the estimated location for the fat-free dry body mass QTL was within the $95 \%$ confidence interval for the 10 -week live mass QTL. Body fat also showed significant linkage $\left(F=6.6\right.$ vs. $\left.F_{0.01}=6.6\right)$, although the estimated effect size in phenotypic standard deviation units was much smaller (Tab. III). 
Table III. Map positions and phenotypic effects of QTL affecting growth traits estimated by interval mapping of the original and new $F_{2}$ populations. The additive effect is half the difference between the low-line and high-line homozygotes, where a positive value indicates that high-line $>$ low-line. The dominance effect is the difference between the heterozygote phenotype and the mean of the two homozygotes, where a positive value indicates that the heterozygote is closer to the high homozygote. The effect in phenotypic standard deviation units is the absolute effect size divided by the standard deviation of the entire sample (using residuals from the sex-specific means so that the sexual dimorphism does not contribute to the standard deviation). The proportional effect size is the absolute effect multiplied by 100 and divided by the mean value for the trait. Values are provided $\pm \mathrm{SE}$.

\begin{tabular}{|c|c|c|c|c|c|c|c|c|}
\hline & \multirow[t]{2}{*}{$N$} & \multirow{2}{*}{$\begin{array}{c}\text { Map } \\
\text { position } \\
(\mathrm{cM})\end{array}$} & \multicolumn{2}{|c|}{$\begin{array}{l}\text { Absolute effect }(\mathrm{g}) \\
(\mathrm{g})\end{array}$} & \multicolumn{2}{|c|}{$\begin{array}{l}\text { Phenotypic standard } \\
\text { deviation units }\left(\sigma_{\mathrm{P}}\right)\end{array}$} & \multicolumn{2}{|c|}{$\begin{array}{c}\text { Proportional effect } \\
(\%)\end{array}$} \\
\hline & & & $\begin{array}{l}\text { Additive } \\
\text { effect }\end{array}$ & $\begin{array}{c}\text { Dominance } \\
\text { effect }\end{array}$ & $\begin{array}{c}\text { Additive } \\
\text { effect }\end{array}$ & $\begin{array}{c}\text { Dominance } \\
\text { effect }\end{array}$ & $\begin{array}{l}\text { Additive } \\
\text { effect }\end{array}$ & $\begin{array}{c}\text { Dominance } \\
\text { effect }\end{array}$ \\
\hline \multicolumn{9}{|l|}{ Original $F_{2}$ population } \\
\hline 10-week body mass (g) & 334 & 6 & $1.72 \pm 0.33$ & $-0.13 \pm 0.50$ & $0.41 \pm 0.08$ & $-0.03 \pm 0.12$ & $6.0 \pm 1.1$ & $-0.4 \pm 1.7$ \\
\hline 6-week body mass (g) & 330 & 7 & $1.21 \pm 0.29$ & $-0.07 \pm 0.43$ & $0.32 \pm 0.08$ & $-0.02 \pm 0.12$ & $5.2 \pm 1.2$ & $-0.3 \pm 1.9$ \\
\hline Fat-free dry body mass $(\mathrm{g})$ & 326 & 32 & $0.42 \pm 0.09$ & $0.09 \pm 0.13$ & $0.39 \pm 0.08$ & $0.09 \pm 0.12$ & $5.8 \pm 1.2$ & $1.3 \pm 1.8$ \\
\hline Fat content $(\mathrm{g})$ & 326 & 0 & $0.23 \pm 0.09$ & $0.29 \pm 0.13$ & $0.20 \pm 0.08$ & $0.25 \pm 0.11$ & $7.5 \pm 3.0$ & $9.5 \pm 4.3$ \\
\hline \multicolumn{9}{|l|}{ LinH $F_{2}$ population } \\
\hline 10-week body mass (g) & 139 & 15 & $1.38 \pm 0.35$ & $0.22 \pm 0.50$ & $0.39 \pm 0.10$ & $0.06 \pm 0.14$ & $3.49 \pm 0.90$ & $0.56 \pm 1.27$ \\
\hline \multicolumn{9}{|l|}{ HinL $F_{2}$ population } \\
\hline 10-week body mass (g) & 116 & 16 & $0.83 \pm 0.23$ & $-0.08 \pm 0.31$ & $0.47 \pm 0.13$ & $-0.04 \pm 0.17$ & $4.70 \pm 1.30$ & $-0.45 \pm 1.74$ \\
\hline \multicolumn{9}{|l|}{ LinH and HinL combined } \\
\hline 10-week body mass $(\mathrm{g})^{\mathrm{a}}$ & 225 & 16 & - & - & $0.42 \pm 0.08$ & $0.01 \pm 0.11$ & - & - \\
\hline
\end{tabular}

${ }^{a}$ For the analysis combining the LinH and HinL populations, the 10-week body mass data were first transformed to have a mean of 0 and a standard deviation of 1 within each sex and population; the resulting estimates are therefore in phenotypic standard deviation units. 
The estimated location of the body fat QTL was just outside the 95\% confidence interval for the 10-week live mass QTL and the shape of the F-value plot differed substantially between body fat and the other traits. However, given the estimated effect sizes and the sample size, the power to distinguish between linkage of two QTL affecting lean body mass and body fat separately versus one pleiotropic QTL affecting both traits would be extremely low [18].

\subsection{LinH and HinL line $F_{2}$ populations}

In the original $\mathrm{F}_{2}$ population, the effects of the QTL were strongest for 10week body mass (Tab. III) and therefore in the new $F_{2}$ populations we focused exclusively on this trait. In both the $\mathrm{LinH}$ and the HinL $\mathrm{F}_{2}$ populations, body mass at 10 weeks showed a significant QTL (LinH: $\mathrm{F}=7.7$ vs. $\mathrm{F}_{0.01}=6.4$; HinL: $\mathrm{F}=6.6$ vs. $\mathrm{F}_{0.01}=6.2$; Fig. $1 \mathrm{~B}$ ). The absolute size of the additive effect was larger in the LinH line than in the HinL line (Tab. III), but the average body mass in the former line was also much higher than in the latter (Tab. II). When expressed as phenotypic standard deviation units, the estimated additive effects in the two new $F_{2}$ populations are similar to that in the original $F_{2}$ population (Tab. III). As in the original $\mathrm{F}_{2}$ population, the estimated dominance effects in the new $F_{2}$ populations are not significantly different from zero (Tab. III). In two-QTL analyses, the F-value for the addition of a second QTL was not significant in either of the new populations ( $\mathrm{LinH}: \mathrm{F}=1.6 v s . \mathrm{F}_{0.05}=5.1$; HinL: $\left.\mathrm{F}=1.5 v s . \mathrm{F}_{0.05}=4.7\right)$. As in the original $\mathrm{F}_{2}$ population, analysing the sexes separately yielded similar results (data not shown).

The estimated locations of the QTL in the two new $F_{2}$ populations were very close, and about in the middle of the $95 \%$ confidence interval obtained for the original $\mathrm{F}_{2}$ population (see above). The $95 \%$ confidence interval for the location of the QTL determined by bootstrapping was 5 to $55 \mathrm{cM}$ for the LinH line and 0 to $32 \mathrm{cM}$ for the HinL line. Because the estimated effects and locations of the QTL in the two new $F_{2}$ populations were in such good agreement, the data were combined to obtain a better estimate of the location of the QTL. Mean body mass and the absolute additive effect of the QTL differed between the two lines (Tabs. II and III) and therefore the raw 10-week body mass data were transformed to have a mean of 0 and a standard deviation of 1 within each sex and population (i.e., by subtracting the mean and dividing by the standard deviation of the appropriate sex and population). The estimated location of the QTL in the combined analysis was $16 \mathrm{cM}$ and the F-value was highly significant $\left(\mathrm{F}=14.1 \mathrm{vs} . \mathrm{F}_{0.01}=6.8\right)$; again there was no support for the existence of a second QTL ( $\left.\mathrm{F}=2.7 v s . \mathrm{F}_{0.05}=4.6\right)$. The $95 \%$ confidence 
interval for the location of the QTL was refined to the region from 10 to $16 \mathrm{cM}$ (inclusive).

Combining the data from the original and new $\mathrm{F}_{2}$ populations did not reduce the confidence interval further or provide significant support for a second QTL (data not shown).

Although the absolute additive effect was higher in the LinH line than in the HinL line (Tab. III), the additive by line interaction was not significant for the test of epistasis performed on the untransformed body masses or the standardised data $(P>0.15$ in both cases). Similarly, the dominance by line interaction was not significant $(P>0.2)$ and thus there was no evidence that the effect of the QTL differed in the two genetic backgrounds.

\subsection{Body mass in the fixed introgression lines}

Figure 2 shows mean body mass in the introgression lines at each generation throughout introgression, in the fixed lines after introgression (i.e., in which the introgressed allele was present but not segregating), and in the inbred high and low lines. To confirm that the introgressed QTL alleles had been successfully fixed in the alternate genetic backgrounds, body mass at 10 weeks in each fixed line was compared with that in the contemporaneous generation of the corresponding inbred line (i.e., the LinH fixed line vs. the high line and vice versa) using a general linear model with sex as an additional factor in the model and litter size as a covariate. There was a significant effect of line in both the LinH versus high and HinL versus low comparisons $\left(\mathrm{F}_{1,170}=29.90\right.$ and $\mathrm{F}_{1,65}=85.87$, respectively; $P<0.0001$ for both tests). The LinH line was $2.85 \pm 0.52 \mathrm{~g}$ lighter than the high line, which is roughly what is expected given twice the additive effect of the QTL estimated in the $\mathrm{LinH}_{2}$ population (Tab. III), i.e., $2.76 \mathrm{~g}$. However, the HinL line was $4.25 \pm 0.46 \mathrm{~g}$ heavier than the low line, a difference which is substantially greater than that expected given twice the additive estimate from the HinL $\mathrm{F}_{2}$ population (Tab. III), i.e., $1.66 \mathrm{~g}$, suggesting that high alleles at other QTL, perhaps on other chromosomes, were also introgressed.

\section{DISCUSSION}

In this study, we have identified a QTL affecting 10-week body mass in a cross between two lines of mice divergently selected for growth and confirmed the magnitude of its effect by introgressing each of the QTL alleles into the alternate genetic background. The estimated additive effect of the QTL on body 


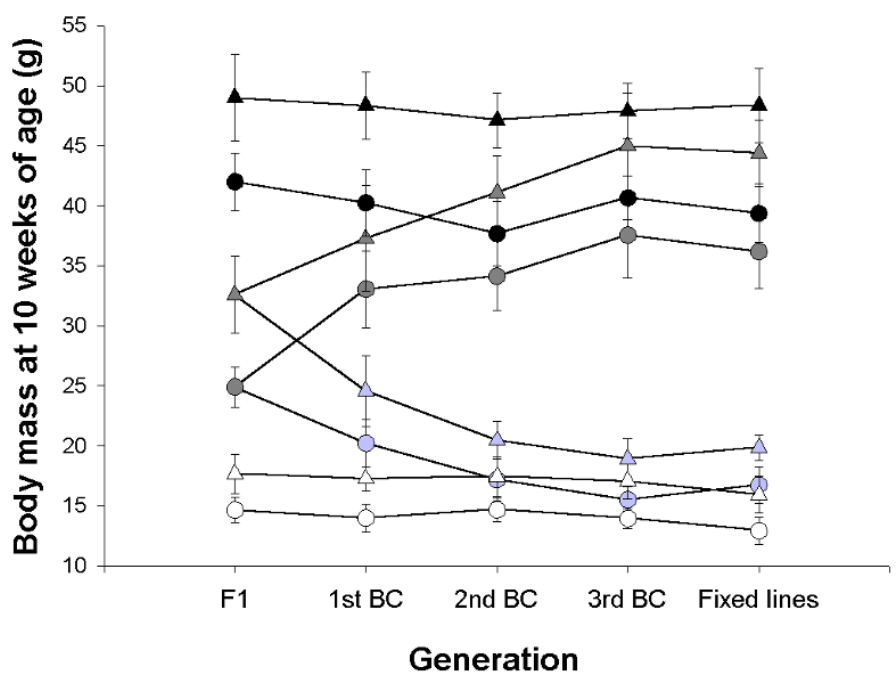

Figure 2. Mean 10-week body mass throughout the introgression and in the lines in which the introgressed allele has been fixed in the LinH (dark grey symbols) and HinL (light grey) lines for females (circles) and males (triangles). Values in the contemporaneous generations of the high (black) and low (white) lines are also shown. Sample sizes for each data point range from 12 to 56 (mean: 29) and are generally larger by about 10 individuals in the high and LinH lines due to larger litter sizes. Error bars show the standard deviations.

mass was not significant at 3 weeks of age but was significant at 6 weeks and was even greater at 10 weeks, indicating that this QTL influences the middle and late growth periods [28]. The effect of the QTL was not sex-specific. Body composition analysis of the original $\mathrm{F}_{2}$ population showed that the QTL affected lean mass. Although an effect on fat mass was also detected, it is not clear whether this was due to pleiotropic effects of the lean mass QTL, or to the effect of a separate locus.

The 95\% confidence interval for the location of the QTL obtained from the original $\mathrm{F}_{2}$ population was much larger $(39 \mathrm{cM})$ than that obtained from the combined analysis of the new $\mathrm{F}_{2}$ populations $(7 \mathrm{cM})$, even though the sample size in the former analysis $(N=334)$ was substantially larger than that in the latter $(N=225)$. One likely reason for this result is that not all of the families in the original $\mathrm{F}_{2}$ population were informative (see above). Another possible explanation is that more than one allele at the QTL may have been segregating within the outbred high line used to generate the original $F_{2}$ population. Alternatively, more than one QTL affecting body mass may have been segregating in the original $F_{2}$ population, one of which was lost during inbreeding of the 
high line prior to the introgression. These possibilities could also explain differences in the shape of the F-value plots obtained from the original and new $\mathrm{F}_{2}$ populations (Fig. 1).

There was significant support for the presence of the QTL when it was introgressed into both the high and low lines, and the additive and dominance effects did not differ significantly in the two genetic backgrounds. No interaction between genetic background and effect size was detected regardless of whether the untransformed data were analysed (yielding the absolute effect size in grams) or whether the data were first scaled to the within-line variation (yielding an estimate in phenotypic standard deviation units). Evidence of epistasis is found frequently in genome-wide QTL analyses of body size $[1,17,24,30]$ although in most cases not all QTL are involved in epistatic interactions (but see [5]). The lack of interaction between genetic background and the QTL identified in this study may indicate that this particular QTL does not participate in epistatic interactions with other loci, or that its interactions with a number of loci negate each other.

A recent review [7] lists a number of other studies that have found QTL affecting murine growth on chromosome 6 , however none of the estimated locations of these QTL are within the 95\% confidence interval of the QTL identified in this study. This target region is less than $7 \mathrm{cM}$ and contains approximately 100 genes according to the Ensembl database [8]. These include insulin-like growth factor 2 binding protein 3 (Igf2bp3) at $49.4 \mathrm{MB}$, fibroblast growth factor inducible protein 15 (Fin15) at $50.6 \mathrm{MB}$, and growth hormonereleasing hormone receptor precursor $(G h r h r)$ at $55.8 \mathrm{MB}$ [8]. A known mutation in the latter gene (the little mutation) causes dwarfism in mice [11] and has been shown to reduce growth in both of the parental lines used this study [4]. While it is tempting to focus on such candidate genes, it is important to note that the effects of the QTL may be due to another, less obvious gene or genes in the region, including gene(s) whose functions are currently unknown.

\section{ACKNOWLEDGEMENTS}

We are grateful to the BBSRC (UK), NSERC (Canada) and Royal Society (UK) for financial support, to Adrian White and Charlotte Bruley for technical assistance and supervision, to Ian Hastings for his contribution during the initial stages of this study and to Bill Hill for his helpful comments. 


\section{REFERENCES}

[1] Brockmann G.A., Kratzsch J., Haley C.S., Renne U., Schwerin M., Karle S., Single QTL effects, epistasis, and pleiotropy account for two- thirds of the phenotypic F-2 variance of growth and obesity in DU6i $\times$ DBA/2 mice, Genome Res. 10 (2000) 1941-1957.

[2] Bünger L., Hill W.G., Effects of leptin administration on long-term selected fat mice, Genet. Res. 69 (1997) 215-225.

[3] Bünger L., Hill W.G., Inbred lines of mice derived from long-term divergent selection on fat content and body weight, Mamm. Genome 10 (1999) 645-648.

[4] Bünger L., Hill W.G., Role of growth hormone in the genetic change of mice divergently selected for body weight and fatness, Genet. Res. 74 (1999) 351-360.

[5] Cheverud J.M., Vaughn T.T., Pletscher L.S., Peripato A.C., Adams E.S., Erikson C.F., King-Ellison K.J., Genetic architecture of adiposity in the cross of LG/J and SM/J inbred mice, Mamm. Genome 12 (2001) 3-12.

[6] Churchill G.A., Doerge R.W., Empirical threshold values for quantitative trait mapping, Genetics 138 (1994) 963-971.

[7] Corva P.M., Medrano J.F., Quantitative trait loci (QTLs) mapping for growth traits in the mouse: A review, Genet. Sel. Evol. 33 (2001) 105-132.

[8] Ensembl Mouse Genome Server Database. http://www.ensembl.org/Mus_musculus/[consulted: March 2003].

[9] Falconer D.S., Mackay T.F.C., Introduction to Quantitative Genetics, Fourth Edition, Prentice Hall, Harlow, Essex, 1996.

[10] Glazier A.M., Nadeau J.H., Aitman T.J., Finding genes that underlie complex traits, Science 298 (2002) 2345-2349.

[11] Godfrey P., Rahal J.O., Beamer W.G., Copeland N.G., Jenkins N.A., Mayo K.E., GHRH receptor of little mice contains a missense mutation in the extracellular domain that disrupts receptor function, Nature Genet. 4 (1993) 227-232.

[12] Gootwine E., Zenu A., Bor A., Yossafi S., Rosov A., Pollott G.E., Genetic and economic analysis of introgression the B allele of the FecB (Booroola) gene into the Awassi and Assaf dairy breeds, Livest. Prod. Sci. 71 (2001) 49-58.

[13] Green P., Falls K., Crooks S., Documentation for CRI-MAP, version 2.4. http://compgen.rutgers.edu/multimap/crimap/ [consulted: March 2003].

[14] Haley C.S., Visscher P.M., Strategies to utilize marker-quantitative trait loci associations, J. Dairy Sci. 81 (1998) 85-97.

[15] Hastings I.M., Hill W.G., A note on the effect of different selection criteria on carcass composition in mice, Anim. Prod. 48 (1989) 229-233.

[16] Horvat S., Bunger L., Falconer V.M., Mackay P., Law A., Bulfield G., Keightley P.D., Mapping of obesity QTLs in a cross between mouse lines divergently selected on fat content, Mamm. Genome 11 (2000) 2-7.

[17] Ishikawa A., Matsuda Y., Namikawa T., Detection of quantitative trait loci for body weight at 10 weeks from Philippine wild mice, Mamm. Genome 11 (2000) 824-830.

[18] Knott S.A., Haley C.S., Multitrait least squares for quantitative trait loci detection, Genetics 156 (2000) 899-911. 
[19] Liu X.J., Oliver F., Brown S.D.M., Denny P., Keightley P.D., High-resolution quantitative trait locus mapping for body weight in mice by recombinant progeny testing, Genet. Res. 77 (2001) 191-197.

[20] Mackay T.F.C., The genetic architecture of quantitative traits, Annu. Rev. Genet. 35 (2001) 303-339.

[21] Mouse Genome Informatics Web Site, The Jackson Laboratory, Bar Harbor, Maine. http://www.informatics.jax.org/ [consulted: March 2003].

[22] Nadeau J.H., Modifier genes in mice and humans, Nat. Rev. Genet. 2 (2001) $165-174$.

[23] Rance K.A., Hill W.G., Keightley P.D., Mapping quantitative trait loci for body weight on the $\mathrm{X}$ chromosome in mice. I. Analysis of a reciprocal F-2 population, Genet. Res. 70 (1997) 117-124.

[24] Routman E.J., Cheverud J.M., Gene effects on a quantitative trait: Two-locus epistatic effects measured at microsatellite markers and at estimated QTL, Evolution 51 (1997) 1654-1662.

[25] SAS ${ }^{\circledR}$ Institute, SAS/STAT User's Guide, Version 6, Fourth Edition, Volume 2, SAS ${ }^{\circledR}$ Institute Inc., Cary, NC, 1989.

[26] Seaton G., Haley C., Knott S., Kearsey M., Visscher P., QTL express (2002) http://qtl.cap.ed.ac.uk [consulted: March 2003].

[27] Sharp G.L., Hill W.G., Robertson A., Effects of selection on growth, body composition and food intake in mice. 1. Responses in selected traits, Genet. Res. 43 (1984) 75-92.

[28] Vaughn T.T., Pletscher L.S., Peripato A., King-Ellison K., Adams E., Erikson C., Cheverud J.M., Mapping quantitative trait loci for murine growth: a closer look at genetic architecture, Genet. Res. 74 (1999) 313-322.

[29] Visscher P.M., Thompson R., Haley C.S., Confidence intervals in QTL mapping by bootstrapping, Genetics 143 (1996) 1013-1020.

[30] Wolf J.B., Vaughn T.T., Pletscher L.S., Cheverud J.M., Contribution of maternal effect QTL to genetic architecture of early growth in mice, Heredity 89 (2002) 300-310.

[31] Yancovich A., Levin I., Cahaner A., Hillel J., Introgression of the avian naked neck gene assisted by DNA fingerprints, Anim. Genet. 27 (1996) 149-155. 